\title{
Professional training in nutrition in Central and Eastern Europe: current status and opportunities for capacity development
}

\author{
Mirjana Gurinović1,* , Romana Novaković ${ }^{1}$, Zvonimir Šatalić ${ }^{2}$, Marina Nikolić ${ }^{1}$, \\ Jelena Milešević ${ }^{1}$, Marija Ranić ${ }^{1}$ and Marija Glibetić ${ }^{1}$ \\ ${ }^{1}$ Centre of Research Excellence in Nutrition and Metabolism, Institute for Medical Research, University of \\ Belgrade, Tadeuša Košćuška 1, 11000 Belgrade, Serbia: ${ }^{2}$ Faculty of Food Technology and Biotechnology, \\ University of Zagreb, Zagreb, Croatia
}

Submitted 21 May 2013: Final revision received 24 September 2013: Accepted 31 January 2014: First published online 27 February 2014

\begin{abstract}
Objective: To examine the availability of academic programmes in nutrition and identify nutrition training needs in Central and Eastern Europe (CEE).

Design: A questionnaire with close-ended and open-ended questions was distributed to the members of the United Nations University Standing Committee on Nutrition, Regional Network for Capacity Development in Nutrition in CEE (NCDN CEE).

Setting: Participants' responses to the questionnaire including the comments of their colleagues from home institutions were obtained in group discussions during NCDN CEE meetings in 2010-2013.

Subjects: Sixteen CEE countries' experts and their colleagues from home institutions involved in NCDN CEE activities 2007-2013.

Results: The responses were obtained from fourteen out of sixteen participating countries; five countries have established Bachelor, Master and PhD studies in nutrition (Croatia, Czech Republic, Poland, Slovak Republic and Slovenia), whereas in Latvia and Republic of Macedonia only Bachelor and Master studies are set up. Seven countries have no Bachelor, Master or PhD studies: Bosnia and Herzegovina, Bulgaria, Estonia, Lithuania, Montenegro, Romania and Serbia. Introduction to data analysis and Nutritional epidemiology are the most needed nutrition trainings that would increase working competence of nutritionists and nutrition-related professionals in CEE.

Conclusions: Availability of academic programmes in nutrition in CEE countries is limited. Opportunities for improving the competence of existing and future nutrition-related professionals should be addressed at national and regional level; distance learning courses and creation of a regional centre for nutrition training were seen as opportunities for sustainable capacity development in nutrition in CEE.
\end{abstract}

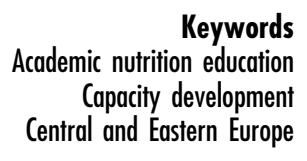

The competence and skills of nutritionists and public health nutritionists are needed to: (i) assess the nutritional situation of populations; (ii) analyse the relationships between nutrition, society and health; and (iii) develop, plan, implement and evaluate approaches for improving the well-being of individuals, communities and the population as a whole, through optimal food and nutrition $^{(1-3)}$. Their activities can be done through capacity development (CD), which basically refers to the ability of societies to carry out a stated objective ${ }^{(4)}$. Specifically, CD in food and nutrition includes formal training, human resource development, and organizational, institutional and legal framework development with the aim of enhancing nutritional knowledge and skills ${ }^{(5-8)}$. CD has been recognized by authorities such as the United Nations
University System Standing Committee on Nutrition (UNU/ SCN) and by the European Commission as an important complementary activity for improving the nutrition situation throughout the world ${ }^{(6,9)}$. The UNU/SCN established a special working group on CD aiming to coordinate and promote activities in partnership with country representatives in nutrition worldwide. Among the most recently founded UNU/SCN regional networks for CD in nutrition is the one in Central and Eastern Europe (CEE), namely the Network for Capacity Development in Nutrition in Central and Eastern Europe $(\mathrm{NCDN} \mathrm{CEE})^{(8)}$. It was set up to: (i) initiate and support CD activities in developing research and training in public nutrition based on country-specific needs in the CEE region; and (ii) involve individuals, groups and institutions in the field of nutrition with the aim 
of sharing and enhancing experiences relevant for nutritional knowledge and skills in the region. During the NCDN CEE annual meetings (2006-2013), nutrition-related professionals from academia, research and public health institutions from CEE and nutrition experts from Western Europe discussed the opportunities and challenges for regional $\mathrm{CD}$ in public health nutrition ${ }^{(10)}$. Because $\mathrm{CD}$ starts with education and training for the development of competent personnel ${ }^{(11)}$, the opportunities for academic training in nutrition in CEE were discussed. It was recognized that the possibilities for earning Bachelor, Master and $\mathrm{PhD}$ degrees in nutrition differ across CEE countries. Insufficient number of nutrition professionals and/or inadequate competencies in nutrition practice could be barriers to carry out nutritional research and to conduct public health nutrition strategies ${ }^{(12)}$. For example, a recent review of micronutrient intake and status in CEE showed a substantial lack of nutritional data for many life stages ${ }^{(13)}$. Nutritionists and public health professionals who have the core elements of training are needed to conduct the research and give better insight into the nutritional status of CEE populations.

The purpose of the present study was to assess the availability of academic programmes in nutrition and to identify the needs for continuing professional development among nutritionists and public health professionals engaged in public health nutrition in CEE, using the information obtained from national experts in nutrition participating in NCDN CEE activities during 2006-2013.

\section{Methods}

To evaluate the existing forms and needs for nutritional training* in CEE, in April 2010 a comprehensive questionnaire was developed and distributed via email to one national expert per country involved in the NCDN CEE (Albania, Bosnia and Herzegovina, Bulgaria, Croatia, Czech Republic, Estonia, Hungary, Latvia, Lithuania, Montenegro, Poland, Republic of Macedonia, Romania, Serbia, Slovak Republic and Slovenia). The participants were persons who took part in the Task Force for CD in CEE established at the NCDN CEE kick-off meeting in 2005, or the candidates for the NCDN CEE follow-up meetings proposed either by NCDN CEE representatives or those who were identified by the WHO, FAO and other authorities $^{(6-8)}$. Overall, they made a good spread over academia, public health and research institutions in CEE.

All countries participating in the study have adopted the Bologna Process, which means that the academic training, where available, is structured in terms of first,

\footnotetext{
* A distinction should be made with respect to the definition of nutrition education. The present paper focuses on nutrition training needs, rather than on a set of learning experiences designed for a specific population group, to facilitate the voluntary adoption of eating and other nutritionrelated behaviours favourable to health and well-being ${ }^{(14)}$.
}

second and third cycles of studies (Bachelor, Master and $\mathrm{PhD})^{(15)}$. The questionnaire involved queries about respondent characteristics (personal details, educational and employment background) and close-ended multiplechoice questions on: (i) the availability of academic programmes in nutrition in the respondents' country (yes/no answers for the categories: Bachelor, Master and PhD studies, reflecting 3-4 years of education, 1-3 years of education or a programme leading to doctoral degree, respectively); and (ii) nutrition training needs which the respondents would necessitate for their own institution (yes/no answers for the categories: Introduction to data analysis, Research methods in nutrition, Statistics for nutritionists, Nutritional epidemiology, Meta-analyses, Dietary intake assessment, Nutritional risk assessment, Nutrition recommendations, Biomarkers of nutritional status, Obesity management, Nutrition transition, Public health/community nutrition practice, Nutrition policy, Practical cooking skills and Communication skills). The list of training needs was made based on group discussion during the NCDN CEE meeting in June 2010 and accounting for the courses in food and nutrition that are commonly offered in academic education in Western European countries. In addition, the respondents were asked if they (or their colleagues) would be interested in web-based distance learning courses that would meet their training needs. Finally, the questionnaire ended up with an open-ended question allowing respondents to add optional training needs that were not already listed and to give other comments and suggestions relevant for the survey. Prior to circulation of the questionnaire, several members of the Network (country representatives from Croatia and Macedonia) were asked to check the clarity of the questionnaire. Afterwards, necessary modifications and translations were made. The questionnaire was sent by email to the Network members with the request to respond or to forward it to their workplace colleagues in case they were not available or competent to fill it in. The questionnaires were collected during 2010-2011 including two remainder notices that were sent to non-responders.

In 2012 the questionnaires were analysed by calculating the frequency of responses; the results were presented to members of the NCDN CEE at the following meeting in January 2013. During group discussion, they gave their comments and update of the findings, as well as other impressions relevant for the study objective.

\section{Results}

Out of sixteen participating CEE countries, a response was obtained from all countries with the exception of Albania and Hungary. Among fourteen respondents, six were employed in academia as associated professors, assistant professors or head of departments (Faculty of 
Medicine, Medical University Varna 'Prof. Dr. Paraskev Stoyanov', Varna, Bulgaria; Faculty of Food Technology and Biotechnology, University of Zagreb, Zagreb, Croatia; Tallinn University of Technology, Tallinn, Estonia; Technical University of Moldova, Chisinau, Republic of Moldova; Faculty of Human Nutrition and Consumer Sciences, Warsaw University of Life Sciences, Warsaw, Poland; University of Medicine and Pharmacy, Cluj-Napoca, Romania), while others worked in national institutes for public health or research institutions (National Institute for Public Health, Prague, Czech Republic; Ministry of Agriculture Food and Veterinary Service, Riga, Latvia; Health Education and Diseases Prevention Centre at Ministry of Health, Vilnius, Lithuania; Institute of Public Health, Skopje, Macedonia; Institute of Public Health, Podgorica, Montenegro; Centre of Research Excellence in Nutrition and Metabolism, Institute for Medical Research, University of Belgrade, Serbia; Public Health Authority of the Slovak Republic, Bratislava; Department of Food Science and Technology, University of Ljubljana, Slovenia).

The possibilities for earning Bachelor, Master and $\mathrm{PhD}$ studies in nutrition are offered in Croatia, Czech Republic, Poland, Slovak Republic and Slovenia, whereas in Latvia and Republic of Macedonia only Bachelor and Master studies are established. In the latter two countries interdisciplinary $\mathrm{PhD}$ programmes at faculties of biotechnology, agriculture and medicine offer some nutrition modules; however, a doctoral degree in nutrition per se cannot be earned. In the other seven countries (Bosnia and Herzegovina, Bulgaria, Estonia, Lithuania, Montenegro, Romania and Serbia) Bachelor, Master and $\mathrm{PhD}$ programmes in nutrition are not offered. In these countries, professional nutritional training can be pursued as a distinct medical subspecialty in hygiene after completing 6 years of medical study.

Table 1 shows identified needs for continuing professional development in nutrition: the number of courses of interest per country and the number of countries interested in each course are shown in columns and rows, respectively. Out of fifteen courses listed in the questionnaire, the highest interest was expressed for Nutritional epidemiology: thirteen out of fourteen participating countries, followed by Introduction to data analysis, Statistics for nutritionists and Research methods in nutrition (twelve countries interested for each course). Nutritional risk assessment was in demand among eleven respondents, whereas Dietary intake assessment and Nutrition recommendations were required by ten participating countries. Meta-analyses, Biomarkers of nutritional status and Communication skills were requested by nine respondents, followed by Public health/community nutrition practice, Nutrition policy and Obesity management (eight, eight and seven countries, respectively). Nutrition transition and Practical cooking skills were reportedly least needed for professional development as they were chosen by five and four participants, respectively.

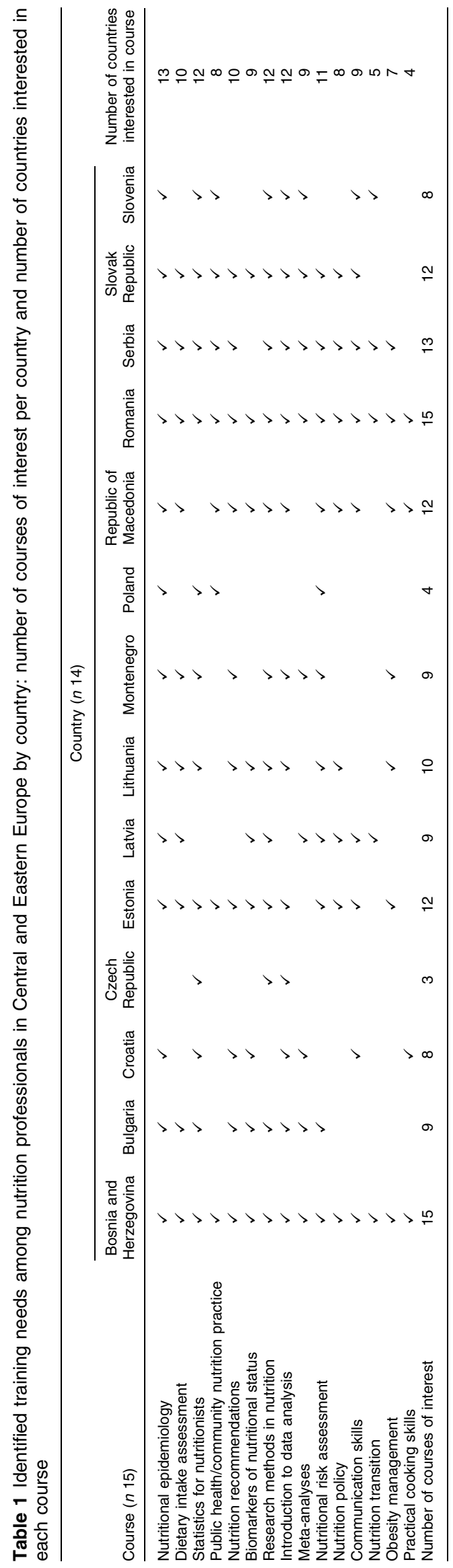


Additional courses of interest not listed but mentioned by the respondents were Nutrition consulting practice (Estonia) and Vegetarian nutrition (Croatia). The webbased distance courses were recognized as learning opportunities by respondents from Bulgaria, Croatia, Czech Republic, Macedonia, Montenegro and Romania. However, all answers with an exception of Romania (no comment provided) were with the impression that face-to-face interactions with course providers should either precede and/or complement e-learning modules to clarify uncertainties and improve the learning process. Out of fifteen training needs offered in the questionnaire, participants from Czech Republic and Poland opted for the least: three and four courses, respectively, whereas members from other countries showed interest in eight or more topics. Respondents from Bosnia and Herzegovina and Romania were interested in all courses listed in the questionnaire.

In January 2013, during the group discussion it was emphasized that a supportive policy environment from national governments is needed for establishing academic programmes in nutrition and for accreditation and certification of the job title for nutritionists (licensed or registered), otherwise any effort would fail. Distance learning courses and creation of a regional centre for nutrition training were seen as opportunities for sustainable $\mathrm{CD}$ in nutrition in CEE.

\section{Discussion}

The present paper outlines the status of academic programmes in nutrition offered in CEE, as well as identifies training needs for the professionals involved in public health nutrition activities. Because Bachelor and Master programmes in nutrition are said to be 'absent' in seven and $\mathrm{PhD}$ programmes in nine CEE countries, their establishing or expanding is clearly urgently needed. As indicated by the European Commission, to set up a quality higher education system (bachelor/master/doctorate), a collective effort of public authorities, universities, teachers and students, together with international organizations and institutions, is needed ${ }^{(16)}$. The outcome of the present study can help to set up short- and/or long-term goals relevant for identified educational and training needs. It was suggested that $\mathrm{CD}$ in nutrition in CEE can be met through a framework of nutrition trainings (short courses, seminars and lectures), in particular via e-learning modules combined with face-to-face sessions. Because of unfavourable socio-economic conditions in CEE, costeffective e-learning modules - which are generally cheaper than their on-campus counterparts ${ }^{(14)}$ - could be suitable for improving some of the identified educational and training needs in CEE.

The study was conducted under the frame of the NCDN CEE which fairly represents countries of the CEE region.
The sampling of the respondents was done through the NCDN CEE which gathered national experts identified by the authorities. Also, responses were relatively easy to obtain, so the results reasonably reflect the current situation in CEE. During the group discussion it was stressed that the highest interest in Nutritional epidemiology involving data analysis and statistics for nutritionists was because such knowledge is needed not only for conducting research, but also to properly comprehend nutritional research evidence in everyday work. This was pointed out by nearly all participants, which means that there is a need to either acquire or update the knowledge on these topics. More information on Nutritional risk assessment (required by all countries but Croatia, Czech Republic and Slovenia) was in demand because it is necessary for understanding and following the guidelines and principles issued by food safety authorities such as the European Food Safety Authority, with which national institutions reportedly cooperate. Dietary intake assessment, Nutrition recommendations, Biomarkers of nutritional status and to some extent Meta-analysis are topics covered in principles of nutritional research and therefore it is no surprise that the interest for these subjects was expressed primarily by those countries which do not have established academic programmes in nutrition. Communication of nutrition information is generally seen as an important part of nutrition professionalism. Moderate interest in this topic was spread across all participating countries regardless of the availability of academic programmes: some of the participants were already familiar with this topic or it was not prioritized in their everyday work. Nearly half of the respondents, of whom most were from the countries where no academic programme in nutrition was established, desired more knowledge in Public health/community nutrition practice, Nutrition policy and Obesity management. Observed lower interest in Nutrition transition and Practical cooking skills in comparison to other topics was allegedly due to the relative simplicity of acquiring that knowledge via open access Internet sources.

Even though the responses came from competent (public health) nutritionists identified primarily by the WHO and FAO, it should be acknowledged that the choice of courses most in demand was based on their anticipated need, and it may not reflect the opinion of other people working in public health nutrition in the respective countries. Still, the results shown in the present paper undoubtedly capture which skills could increase working competences of public health nutritionists in existing settings/circumstances across CEE. Although it might be that not all courses are equally desired across all academic and professional levels, it seems that data analyses skills (Nutritional epidemiology, Introduction to data analysis, Statistics for nutritionists and Research methods in nutrition) are most required among (public health) nutrition practitioners in CEE. Overall, the number 
of selected courses of interest somewhat corresponds to the (non-) existence of the academic nutrition education in the country, e.g. respondents from Bosnia and Herzegovina and Romania showed the highest interest in all topics listed in the questionnaire, whereas those from Czech Republic and Poland selected the least number of the courses.

Clearly, academic programmes in nutrition are necessary for understanding of the role of food intake in relationship to health and disease ${ }^{(16,17)}$. Identified gaps in nutrition training in CEE are barriers to conducting nutritional research to evaluate the nutritional status of CEE populations and to develop and undertake effective population-based strategies to meet nutrition and public health objectives. In addition, trainings for professional development are needed to extend depth of expertise, as competency must be periodically renewed since nutrition science is constantly evolving ${ }^{(3,4,14)}$. The WHO Updated Revised Draft Global Action Plan for the Prevention and Control of Non-communicable Diseases 2013 to 2020 advocates capacity building to address food- and nutrition-related health and health system challenges in Europe $^{(2)}$; it is said that a failure to achieve public health nutrition goals in the past was explained, among other factors, by the lack of expertise. Several publications have defined the competencies and needs for a workforce qualified to deal with public health nutrition in Europe $^{(3,9,11)}$. It has been shown that up-skilling health and community-based professionals in nutrition should be one of the most common capacity building strategies. As the milestone of $\mathrm{CD}$ is the creation of professional networks ${ }^{(7,12)}$, the NCDN CEE as such could be used for training of personnel by setting up short courses or by disseminating learning materials. During the group discussions participants agreed that the host of the NCDN CEE meeting, the Centre of Research Excellence in Nutrition and Metabolism, Belgrade, Serbia (CENM), could be a facilitator of several training courses, namely application of dietary assessment, software tools and food composition database management with hands-on experience, and to certify short trainings in nutrition. The CENM has experience in conducting these courses owing to its involvement in regional and European Commission-funded projects. On the other hand, establishing academic training in nutrition in the countries where these are lacking is a complex task that would require substantial help and support from local governments and other major stakeholders. Yet, only if the messages on identified nutrition training needs as resulting from the present paper are heard can relevant institutions and groups possibly act upon them.

\section{Conclusion}

Opportunities for academic, professional education and training programmes in human nutrition in CEE countries are limited. The Network for CD (NCDN CEE) in cooperation with European Commission-funded projects and other UNU/SCN networks might have a role in setting up courses and workshops to meet some of the identified training needs. Regional CD initiatives by the public health nutrition workforce in partnerships with national governments and academic institutions could help to establish or expand programmes for earning Bachelor, Master and/or Doctoral degrees in nutrition in the countries where these programmes are non-existent.

\section{Acknowledgements}

Sources of funding: This work was supported by the United Nations University Food and Nutrition Programme, the UNU/SCN Network for Capacity Development in Nutrition in Central and Eastern Europe (NCDN CEE) and by the Ministry of Education, Science and Technological Development of the Republic of Serbia, III Project 41030. The funders had no role in the design, analysis or writing of this article. Conflicts of interest: The authors declare no conflicts of interest. Ethical approval: No ethical approval was needed for the study. Authors' contributions: M. Gurinović, M. Glibetić, R.N., Z.Š. and M.N. created the questionnaire. M. Gurinović, M. Glibetić, R.N. and Z.Š. conceptualized and drafted the manuscript. M.N., J.M. and M.R. collected and analysed the questionnaire and helped with revision of the manuscript. Acknowledgements: The authors would like to thank all members of the NCDN CEE who completed the questionnaire. They give special acknowledgment to Professor Arne Oshaug for his work and for supporting NCDN CEE activities during 2006-2013.

\section{References}

1. Torheim LE, Granli GI, Barikmo I et al. (2009) A survey among potential employers for developing a curriculum in public health nutrition. Public Health Nutr 12, 1039-1045.

2. World Health Organization (2013) Updated Revised Draft Global Action Plan for the Prevention and Control of NCDs Covering the Period 2013 to 2020. Copenhagen: WHO Regional Office for Europe.

3. Yngve A, Warm D, Landman J et al. (2001) A European master's programme in public health nutrition. Public Health Nutr 4, 1389-1391.

4. Baillie E, Bjarnholt C, Gruber M et al. (2009) A capacitybuilding conceptual framework for public health nutrition practice. Public Health Nutr 12, 1031-1038.

5. Lopes C \& Theisohn T (2003) Ownership, Leadership and Transformation: Can We Do Better for Capacity Development? New York: Earthscan Publications Ltd.

6. Pavlovic M, Witthoft CM, Hollman P et al. (2009) Training and capacity building in central and eastern Europe through the EuroFIR and CEE networks. Food Chem 113, 846-850.

7. Pavlovic M, Pepping F, Demes M et al. (2009) Turning dilemmas into opportunities: a UNU/SCN capacity development network in public nutrition in Central and Eastern Europe. Public Health Nutr 12, 1046-1051. 
8. Gurinović M, Witthöft CM, Tepšić J et al. (2010) Capacity development in food composition database management and nutritional research and education in Central and Eastern European, Middle Eastern and North African countries. Eur J Clin Nutr 64, Suppl. 3, S134-S138.

9. United Nations University/Standing Committee on Nutrition, Working Group on Capacity Development in Food and Nutrition (2001-2008) Report/Planned Activities. http://www. unscn.org/en/unscn_working_groups/capdev/ (accessed May 2013).

10. Capacity Development Network in Nutrition, Central and Eastern Europe (2006-2013) NCDN CEE meeting reports. http://www.agrowebcee.net/ncdn/ (accessed May 2013).

11. Davies J, Hughes R \& Margetts B (2012) Towards an international system of professional recognition for public health nutritionists: a feasibility study within the European Union. Public Health Nutr 15, 2005-2011.

12. Hughes R \& Margetts B (2012) The public health nutrition intervention management bi-cycle: a model for training and practice improvement. Public Health Nutr $\mathbf{1 5}$, 1981-1988.

13. Novaković R, Cavelaars AE, Bekkering GE et al. (2013) Micronutrient intake and status in Central and Eastern Europe compared with other European countries, results from the EURRECA network. Public Health Nutr 16, 824-840.

14. Food and Agriculture Organization of the United Nations (2011) The Need for Professional Training in Nutrition Education and Communication. Rome: FAO.

15. European Higher Education Area (2013) Bologna Process. http://www.ehea.info/article-details.aspx?ArticleId=86 (accessed August 2013).

16. European Commission (2013) Education and Training. http://ec.europa.eu/education/policy/higher-education/ bologna-process_en.htm (accessed May 2013).

17. Kugelberg S, Jonsdottir S, Faxelid E et al. (2012) Public health nutrition workforce development in seven European countries: constraining and enabling factors. Public Health Nutr 15, 1989-1998. 